\title{
VALORES HEMATOLÓGICOS EM FRANGOS DE CORTE DE CRIAÇÃO INDUSTRIAL
}

\author{
Adriana Borsa \\ Docente do Curso de Medicina Veterinária da Universidade Federal do Mato Grosso (UFMT)
}

\section{RESUMO}

O uso da hematologia representa importante ferramenta para o estabelecimento de diagnóstico de diversas doenças bem como para a compreensão dos mecanismos de patogênese das mesmas. No Brasil existem poucas referências bibliográficas sobre os valores hematológicos aviários, bem como sobre os fatores que podem influenciar estes parâmetros. Tendo em vista estas questões, objetivou-se com este trabalho a determinação dos valores hematológicos de frangos de corte, machos, linhagem comercial, criados em sistema industrial, entre 7 e 42 dias de idade, idade em que normalmente as aves são abatidas. Os resultados demonstraram que o número total de hemácias $(\mathrm{Hm})$ ficou entre 1,69 e 2,03 X 10\% $/ \mu \mathrm{L}$ e o volume globular (VG) entre 29,6 e $33,2 \%$. A taxa de hemoglobina entre 8,26 e $10,38 \mathrm{~g} / \mathrm{dL}$. O número total de leucócitos variou entre 11900 e $18500 \times 10^{3} / \mu \mathrm{L}$. Contudo, as variações dos valores destes parâmetros entre as diferentes faixas etárias não foram consideradas significativas $(p<0,05)$. Concluiu-se com este trabalho que há a necessidade de realização de mais pesquisas na área a fim de melhor estabelecer-se discutir-se os valores hematológicos de referência para frangos de corte no Brasil.

Palavras - chave: avicultura; frangos de corte; sanidade avícola; hematologia; diagnóstico laboratorial

\section{HEMATOLOGICAL VALUES IN BROILER CHICKENS}

\begin{abstract}
The use of hematology is an important tool for establishing the diagnosis of various diseases and for understanding the mechanisms of pathogenesis of them. In Brazil there are few references on avian hematologic values and on the factors that can influence these parameters. In view of these issues, the aim of this work was the determination of hematological values of broiler males, commercial line, reared in the industrial system, between 7 and 42 days of age, where normally the birds are slaughtered. The results showed that the total number of red blood cells $(\mathrm{Hm})$ was between 1.69 and $2.03 \times 10^{6} / \mu \mathrm{L}$ and packed cell volume (PCV) between 29.6 and $33.2 \%$. Hemoglobin level between 8.26 and $10.38 \mathrm{~g} / \mathrm{dL}$. The total number of leukocytes varied between 11900 and $18,500 \times 10^{3} / \mu \mathrm{L}$. However, variations in the values of these parameters between the different age groups were not considered significant $(p<0.05)$. The conclusion of this work that there is a need for more research in the area in order to better establish themselves discuss hematologic values of reference for broiler chickens in Brazil.
\end{abstract}

Keywords: poultry; broiler chickens; avian health; hematology; laboratory diagnosis 


\section{INTRODUÇÃO}

Há aproximadamente 8600 espécies de aves, agrupadas em 27 ordens diferentes. Características próprias as diferenciam dos mamíferos em geral, incluindo aspectos hematológicos e o uricotelismo.

As células sangüíneas das aves compreendem os eritrócitos, leucócitos e trombócitos (STURKIE e GRIMINGER, 1986; CAMPBELL e DEIN,1984). O eritrócito das aves é uma célula ovalada, com presença de núcleo também ovalado localizado centralmente (STURKIE e GRIMINGER, 1986). Na sua contagem total há grande variação dos valores médios e dos limites inferiores e superiores, entre diversas espécies aviárias (CAMPBELL e DEIN,1984; STURKIE e GRIMINGER, 1986).

Bounous e Stedman (2000) verificaram em galinhas um valor médio de $3,0 \times 10^{6}$ eritrócitos/ $\mu \mathrm{L}$; com limite de $2,5 \times 10^{6}$ eritrócitos $/ \mu \mathrm{L}$ a $3,5 \times 10^{6}$ eritrócitos $/ \mu \mathrm{L}$. Mirsalimi e Julian (1991) obtiveram médias de $1,94 \times 10^{6}$ eritrócitos $/ \mu \mathrm{L}$ em frangos de corte e Tessari et al. (2006) verificaram média de $2,5 \times 10^{6}$ eritrócitos/ $\mu \mathrm{L}$ também em frangos de corte.

O volume corpuscular ou globular (VG) é um importante parâmetro para a avaliação clínicolaboratorial dos animais; sendo utilizado para o diagnóstico de anemia. $\mathrm{O}$ método mais rápido e prático para sua avaliação é a técnica do microhematócrito (CAMPBELL e COLES, 1986). Campbell e Dein (1984) citam como sendo de $35 \%$ a $55 \%$ a variação normal do VG aviário e Bounous e Stedman (2000), valores de 22 a 35\%. Valores acima de 55\%, de acordo com Campbell e Coles (1986) podem indicar desidratação.

Goodwin et al. (1992) estabeleceram intervalos de referência do hematócrito com o objetivo de serem utilizados como valores de comparação para diagnóstico da anemia e policitemia em frangos de corte. Neste trabalho, os autores verificaram que os valores do VG diminuem significativamente com a idade $(p<0,025)$.

Cardoso e Tessari (2003) verificaram uma variação de 30,6 a $37 \%$ do hematócrito em frangos de corte clinicamente saudáveis; enquanto Tessari et al. (2006) obtiveram uma média de $43,5 \%$.

A quantidade de hemoglobina no sangue aviário é altamente variável. Esta variação pode ser devido a diferentes métodos de determinação. O método da cianometahemoglobina é o mais preciso e utilizado na determinação da hemoglobina nas aves. Em virtude das hemácias serem nucleadas deve-se centrifugar as soluções contendo células lisadas, com a finalidade de remover núcleos, evitando erros de leitura no espectrofotômetro (CAMPBELL e DEIN, 1984; STURKIE e GRIMINGER, 1986; JAIN, 1993).

Segundo Bounous e Stedman (2000) o valor médio da taxa de hemoglobina nas aves é de $9 \mathrm{~g} / \mathrm{dL}$, variando de 7,0 a 13,0 $/ \mathrm{dL}$.

Os índices de Wintrobe (WINTROBE, 1933) denominados como concentração de hemoglobina corpuscular média ( $\mathrm{CHCM}$ ) e volume corpuscular médio (VCM) detectam a presença de anemia e avaliam a capacidade que a medula óssea tem de produzir hemácias de tamanho e capacidade metabólica normais, assim como o conteúdo de hemoglobina.

A contagem de eritrócitos e leucócitos é feita ao mesmo tempo, em câmara de contagem de células de neubauer, mediante o emprego de pipeta de Thomas; a solução para diluição mais recomendada para a hematologia de aves é a solução de Natt e Herrick (1952) pelo método descrito pelos mesmos autores.

Os leucócitos aviários dividem-se de acordo com sua morfologia nuclear. Os agranulócitos são constituídos por linfócitos, monócitos e trombócitos. Os granulócitos são constituídos por heterófilos, eosinófilos e basófilos (CAMPBELL e DEIN, 1984). 
A determinação do número de leucócitos no sangue aviário foi realizada por diversos pesquisadores, entretanto, a interpretação do leucograma aviário é uma tarefa difícil tendo em vista a grande variação ocasionada pela espécie, raça, sexo, linhagem, estação do ano, estresse e fatores ambientais, além da variação dos métodos utilizadas pelos laboratórios (STURKIE e GRIMINGER, 1986).

Possivelmente em decorrência desses fatos, os valores médios e os limites superiores e inferiores detectados por vários autores são bastante variáveis.

Sturkie e Griminger (1986) relatam média de 19.800 leucócitos/ $\mu \mathrm{L}$. Bounous e Stedman (2000) cita valor médio de 21.000 leucócitos/ $\mu \mathrm{L}$, com limites de 12.000 a 30.000 leucócitos $/ \mu \mathrm{L}$. Cunha et al. (1987) verificaram variação de 3.200 a 44.300 leucócitos/ $\mu \mathrm{L}$, trabalhando com frangos de corte em idade de abate; Cardoso e Tessari (2003) verificaram variação de 13920 a 28720 leucócitos/ $\mu \mathrm{L}$ em frangos de corte entre 1 e 52 dias de idade e Tessari et al. (2006) obtiveram média de 24300 leucócitos/ $\mu \mathrm{L}$.

Lucas e Jamroz (1961) citam valores relativos de 64 a $82 \%$ de linfócitos em fêmeas e de $64 \%$ em machos e apontam que em algumas espécies de aves, o linfócito é a célula mais predominante do leucograma. Bounous e Stedman (2000) cita a variação de 12000 a 30000 linfócitos/ $\mu \mathrm{L}$ na galinha doméstica.

Os heterófilos são as células aviárias equivalentes aos neutrófilos dos mamíferos. Os heterófilos maduros tem pouca variação do tamanho, a forma é predominantemente arredondada, grânulos citoplasmáticos em forma de bastão ou fusiformes, podendo apresentar-se arredondados ou elípticos, corando de modo brilhante pela eosina (LUCAS e JAMROZ, 1961).

Bounous e Stedman (2000) cita valores absolutos variando de 3.000 a 6.000 heterófilos $/ \mu \mathrm{L}$, com média de 4.500 heterófilos, afirmando que o heterófilo é a segunda célula mais numerosa. Cunha et al. (1987) relata que em suas pesquisas, o heterófilo foi a célula predominante no sangue de frangos.

Os monócitos são células maiores que os linfócitos, possuindo tamanho similar aos heterófilos. Sua forma geralmente é arredondada ou ligeiramente irregular, com projeções ou se moldando às células vizinhas. Representam 1,0 a $6,5 \%$ dos leucócitos circulantes, com número absoluto médio de 1.500 monócitos/ $\mu \mathrm{L}$ (LUCAS e JAMROZ, 1961), podendo variar, de acordo com Bounous e Stedman (2000) entre 150 a 2000 monócitos/ $\mu \mathrm{L}$.

Os eosinófilos possuem grande variação de tamanho, citoplasma com grânulos eosinofílicos, geralmente esféricos ou em forma de anel, presentes em grande número no citoplasma, podendo, no entanto, ocorrer pequenos grânulos isolados, podendo ser encontrado até 1000 eosinófilos/ $\mu \mathrm{L}$ (BOUNOUS e STEDMAN; 2000).

Os basófilos possuem grânulos com afinidade para corantes básicos e apresentam metacromasia, sendo facilmente identificados nos esfregaços sangüíneos, embora sejam de rara ocorrência (BOUNOUS e STEDMAN; 2000).

Progressos na área de hematologia aviária ainda reservam grandes lacunas em relação à variedade de espécies, raças, idade e outros que podem ser fatores importantes no tocante à variabilidade dos parâmetros hematológicos (SAUKAS, 1993; KANTEK e PACHALY, 1994; DEPTA e KONCIKI, 1999; BOUNOUS e STEDMAN (2000); KOHAYAGAWA et al., 2001; CARDOSO e TESSARI, 2003).

Tendo em vista esta realidade, corroborada pelos resultados das pesquisas na literatura específica, objetivou-se com este trabalho a determinação de valores hematológicos de referência para frangos de corte, machos, linhagem comercial, criados em 
sistema industrial, entre sete e quarenta e dois dias de vida.

\section{MÉTODOS}

Foram utilizados 35 frangos de um lote de 125 animais, machos, linhagem Ross, criados em sistema industrial de criação (LANA, 2000), com ração comercial e água "ad libitum". A cama utilizada foi cepilho de madeira e as aves foram mantidas sob aquecimento elétrico até os 21 dias de idade.

Os frangos eram provenientes de incubatório comercial (Mogi Mirim - SP) e foram vacinados contra doença de Marek, Bouba e Gumboro no primeiro dia de vida. Aos sete, 14, $21,28,35$ e 42 dias de vida foram colhidas amostras de sangue de cinco aves para cada idade, por meio de punção da veia ulnar. Foram utilizadas seringas e agulhas de calibre $25 \times 7$ descartáveis, acondicionando-se as amostras em frascos de vidro contendo anticoagulante EDTA (ácido etilenodiaminotetraacético) a $3 \%$.

As hemácias foram contadas em câmara de neubauer conforme técnica e materiais descritos por Natt e Herrick (1952), bem como a contagem de leucócitos. A determinação do volume globular (VG), hemoglobina $(\mathrm{Hb})$, e os índices de wintrobe, concentração de hemoglobina corpuscular média (CHCM) e volume corpuscular médio (VCM) foram determinados segundo Jain (1993) e Pierson (2000). A contagem diferencial dos leucócitos foi realizada em esfregaços sangüineos, da mesma maneira como para mamíferos, utilizando coloração de Leishman (CAMPBELL e DEIN, 1984; JAIN, 1993) sendo após, realizada a contagem percentual diferenciada de leucócitos por microscopia óptica, seguindo-se os critérios descritos por LUCAS e JAMROZ (1961).

Os resultados obtidos foram submetidos ao teste de comparação de médias (nível de significância de 5\%) utilizando-se o programa $\operatorname{SAS}^{\circledR}(1996)$.

\section{RESULTADOS}

Durante o período em que as aves estiveram alojadas não foram observadas alterações clínicas ou comportamentais. Os índices de produtividade do lote ficaram dentro dos parâmetros considerados normais para a linhagem de frangos de corte comercial (LANA, 2000). A Tab. 1 apresenta os resultados do número total de hemácias $(\mathrm{He})$, volume globular (VG), hemoglobina ( $\mathrm{Hb})$, volume corpuscular médio (VCM) e concentração de hemoglobina corpuscular média (CHCM); a Tab. 2 apresenta o número total de leucócitos (Leuc), heterófilos, linfócitos, monócitos e eosinófilos. Não houve alterações significativas para os valores encontrados em relação à idade das aves. 
Tabela 1 - Número total de hemácias (He), volume globular (VG), taxa de hemoglobina (Hb), volume corpuscular médio (VCM), concentração de hemoglobina corpuscular média ( $\mathrm{CHCM})$, em frangos de corte, machos, linhagem comercial ${ }^{1}$.

\begin{tabular}{lccccc}
\hline $\begin{array}{l}\text { Idade } \\
\text { (dias) }\end{array}$ & \multicolumn{5}{c}{ Parâmetros } \\
\hline & $\mathrm{N}^{\circ} \mathrm{He}$ & $\mathrm{VG}$ & $\mathrm{Hb}$ & $\mathrm{VCM}$ & $\mathrm{CHCM}$ \\
& $\left(10^{6} / \mu \mathrm{L}\right)$ & $(\%)$ & $(\mathrm{g} / \mathrm{dL})$ & $(\mathrm{fL})$ & $(\%)$ \\
7 & $1.72^{\mathrm{a} 2} \pm 0.37$ & $30.60^{\mathrm{a}} \pm 0.55$ & $8.40^{\mathrm{a}} \pm 0.23$ & $185.16^{\mathrm{a}}$ & $27.46^{\mathrm{a}} \pm 0.98$ \\
& & & & \pm 43.53 & \\
14 & $1.69^{\mathrm{a}} \pm 0,11$ & $27.80^{\mathrm{a}} \pm 0,84$ & $8.26^{\mathrm{a}} \pm 0,44$ & $164.60^{\mathrm{a}} \pm 8,61$ & $29.70^{\mathrm{a}} \pm 1,21$ \\
21 & $1.98^{\mathrm{a}} \pm 0,28$ & $33.20^{\mathrm{a}} \pm 1,10$ & $10.38^{\mathrm{a}} \pm 0,44$ & $170.48^{\mathrm{a}}$ & $31.28^{\mathrm{a}} \pm 1,39$ \\
& & & & $\pm 24,83$ & \\
28 & $2.02^{\mathrm{a}} \pm 0,10$ & $30.20^{\mathrm{a}} \pm 0,84$ & $9.54^{\mathrm{a}} \pm 0,41$ & $149.75^{\mathrm{a}} \pm 8,48$ & $31.58^{\mathrm{a}} \pm 0,95$ \\
35 & $2.03^{\mathrm{a}} \pm 0,22$ & $30.40^{\mathrm{a}} \pm 2,51$ & $9.18^{\mathrm{a}} \pm 0,55$ & $150.86^{\mathrm{a}}$ & $30.27^{\mathrm{a}} \pm 1,61$ \\
& & & & $\pm 14,63$ & \\
42 & $1.95^{\mathrm{a}} \pm 0,12$ & $29.60^{\mathrm{a}} \pm 1,52$ & $8.94^{\mathrm{a}} \pm 0,48$ & $152.27^{\mathrm{a}}$ & $30.21^{\mathrm{a}} \pm 1,00$
\end{tabular}

${ }^{1}$ Resultados expressos em média \pm desvio padrão

${ }^{2}$ Médias seguidas pela mesma letra não diferem pelo teste de tukey $(p<0,05)$

Tabela 2 - Contagem total de leucócitos (Leuc), heterófilos, linfócitos, monócitos e eosinófilos em frangos de corte, machos, linhagem comercial ${ }^{1}$

\begin{tabular}{|c|c|c|c|c|c|}
\hline \multirow{3}{*}{$\begin{array}{l}\text { Idade } \\
\text { (dias) }\end{array}$} & \multicolumn{5}{|c|}{ Parâmetros } \\
\hline & \multirow{2}{*}{$\begin{array}{l}\mathrm{N}^{\circ} \text { Leuc } \\
\left(10^{3} / \mu \mathrm{L}\right)\end{array}$} & Heterófilos & Linfócitos & Monócitos & Eosinófilos \\
\hline & & $10^{3} / \mu \mathrm{L}$ & $10^{3} / \mu \mathrm{L}$ & $10^{3} / \mu \mathrm{L}$ & $10^{3} / \mu \mathrm{L}$ \\
\hline \multirow[t]{2}{*}{7} & $18500^{\mathrm{a} 2} \pm 30,7$ & $1306^{a} \pm 73,2$ & $13873^{a} \pm 34,7$ & $1366^{a} \pm 41,5$ & $1956^{a} \pm 65,5$ \\
\hline & & $7 \pm 3,9$ & $74 \pm 6,3$ & $9 \pm 5,7$ & $10 \pm 5,1$ \\
\hline \multirow[t]{2}{*}{14} & $18150^{a} \pm 28,9$ & $2770^{a} \pm 32,2$ & $12766^{a} \pm 38,3$ & $1423^{a} \pm 55,0$ & $1191^{\mathrm{a}} \pm 49,0$ \\
\hline & & $15 \pm 2,2$ & $69 \pm 7,3$ & $8 \pm 5,6$ & $7 \pm 4,9$ \\
\hline \multirow[t]{2}{*}{21} & $11900^{a} \pm 15,6$ & $3876^{a} \pm 60,0$ & $7489^{a} \pm 33,1$ & $56^{\mathrm{a}} \pm 76,0$ & $481^{a} \pm 86,0$ \\
\hline & & $33 \pm 19,6$ & $63 \pm 17,0$ & $0 \pm 0,5$ & $4 \pm 2,9$ \\
\hline \multirow[t]{2}{*}{28} & $12000^{a} \pm 17,2$ & $2998^{a} \pm 32,2$ & $8320^{a} \pm 19,6$ & $289^{a} \pm 101,0$ & $393^{a} \pm 65,8$ \\
\hline & & $25 \pm 6,1$ & $70 \pm 8,0$ & $2 \pm 2,4$ & $3 \pm 2,3$ \\
\hline \multirow[t]{2}{*}{35} & $12900^{a} \pm 20,1$ & $2841^{\mathrm{a}} \pm 36,5$ & $8998^{a} \pm 21,9$ & $525^{a} \pm 123,0$ & $537^{\mathrm{a}} \pm 44,0$ \\
\hline & & $22 \pm 6,3$ & $70 \pm 7,0$ & $4 \pm 4,7$ & $1,4 \pm 3,3$ \\
\hline \multirow[t]{2}{*}{42} & $16700^{a} \pm 28,7$ & $3395^{a} \pm 15,5$ & $12266^{\mathrm{a}} \pm 38,6$ & $256^{a} \pm 103,3$ & $783^{a} \pm 40,8$ \\
\hline & & $22 \pm 6,7$ & $72 \pm 13,4$ & $2 \pm 2,0$ & $5 \pm 2,2$ \\
\hline
\end{tabular}

${ }^{1}$ Resultados expressos em média \pm desvio padrão

${ }^{2}$ Médias seguidas pela mesma letra não diferem pelo teste de tukey $(p<0,05)$ 


\section{DISCUSSÃO}

O curto intervalo entre as colheitas das amostras para exame talvez possa ser a causa da ausência de alterações entre os resultados.

O número de hemácias encontrado ficou de acordo com a média obtida por Mirsalimi e Julian (1991); mas abaixo dos limites obtidos por Jain (1993), Bounous e Stedman; 2000 e Tessari et al. (2006). O limite do volume globular (VG) e hemoglobina $(\mathrm{Hb})$ ficaram dentro da variação apresentada por estes mesmos autores, bem como a concentração de hemoglobina corpuscular média (CHCM) e o volume corpuscular médio (VCM).

Os valores de leucócitos encontrados variaram muito em relação aos níveis de referência obtidos pelos diferentes autores da literatura consultada, que, por sua vez, apresentavam resultados bastante divergentes. Esta variação pode ser atribuída ao "status" sanitário dos lotes, contudo, no presente estudo, as condições sanitárias estavam de acordo com os padrões estabelecidos por Pinheiro (1994); Lana (2000) e Albino e Tavernari (2008).

O linfócito foi a célula mais predominante do leucograma, seguindo-se pelo heterófilo, confirmando Lucas e Jamroz (1961) e Bounous e Stedman; (2000). Já o número de heterófilos foi inferior ao encontrado por Bounous e Stedman (2000).

Em relação aos monócitos e eosinófilos, os valores encontrados no presente estudo ficaram entre os limites publicados por Bounous e Stedman (2000) com exceção ao número de eosinófilos nas duas primeiras semanas de vida, onde observou-se número superior destas células, sugerindo possível resposta à presença de poeira formada pela cama de cepilho de madeira nova. Não foram observados basófilos nos leucogramas analisados, confirmando ser uma célula de rara ocorrência, conforme Lucas e
Jamroz (1961), Bounous e Stedman (2000) e Cardoso e Tessari (2003).

É importante destacar que diversos parâmetros podem influenciar os valores hematológicos, tais como raça e linhagem das aves analisadas, tipo de alimentação, temperatura ambiente, altitude, local da punção venosa, bem como a técnica e o kit laboratorial empregados, dentre outros, justificando assim as diferenças entre os valores encontrados no presente trabalho e de outros autores.

Conclui-se que o presente trabalho foi de suma importância a fim de contribuir para a determinação dos valores de referência dos níveis hematológicos em frangos de corte; porém há necessidade de mais pesquisas nesta área nas condições brasileiras, com o objetivo de obter maiores bases para a discussão sobre os fatores que interferem sobre esses parâmetros.

\section{REFERÊNCIAS}

\section{ALBINO, L.F.T.; TAVERNARI,F.C.de. Produção}

e Manejo de frangos de corte. Viçosa: Ed. UFV, 2008. 88p.

BOUNOUS, D.I.; STEDMAN, N. Normal avian hematology: chicken and turkey. In: FELDMAN,B.F.; ZINKL,J.G.; JAIN, N.C. Schalm's Veterinary Hematology. 5 ed. Philadelphia: Lippincott Williams \& Wilkins, 2000, p.1147-1154. CAMPBELL, T.W.; COLES, E.H. Avian clinical pathology. In: Veterinary Clinical Pathology 4ed. Philadelphia: Lea \& Febiger, 1986, p.279301.

CAMPBELL, T.W.; DEIN, F.J. Avian hematology. The basics. Veterinary Clinical North American., v.14, p.223-248,1984.

CARDOSO, A L.S.P.; TESSARI, E.N.C. Estudo dos parâmetros hematológicos em frangos de corte. Arquivos do Instituto Biológico, v.70, n.4, p.419-424, 2003. 
CUNHA, M.N.M. de A.; GOMES, F.V.B.A.; SOUSA, F.M. de; et al. Leucograma em frangos de corte industrial. In: CONGRESSO BRASILEIRO DE AVICULTURA. 1987, Natal, RN. Anais... Fundação Apinco de Ciência e Tecnologia Avícola, 1987. p.50-51.

DEPTA, K.A.; KONCICKI, A. Physiological values of hematological indices in chickens. Polish Journal Veterinary Science, v.2, n.4, p.165$170,1999$.

GOODWIN, M.A.; DAVIS, J.F.; BROWN, J. Packed cell volume reference intervals to aid in the diagnosis of anemia and polycythemia in young broiler chickens. Avian Diseases, v.36, p.440-443, 1992.

\section{http://dx.doi.org/10.2307/1591525}

JAIN, N.C. Essencials of veterinary

hematology. Philadelphia: Lea \& Febiger, 1993. $417 p$.

KOHAYAGANA, A.; SAUKAS, T.N.; BORETTI, L.P.; et al. Valores hematológicos em frangos de corte de criação industrial no Estado de São Paulo. Revista Brasileira de Ciência Avícola, supl.3, p.82, 2001.

LANA,G.R.Q. Avicultura. Campinas: Ed. Rural, 2000.268p.

LUCAS, A.M., JAMROZ, C. Atlas of avian hematology. Washington: U.S. Department of Agriculture, 1961. $271 p$.

http://dx.doi.org/10.5962/bhl.title.6392

MIRSALIMI, S.M.; JULIAN, R.J. Reduced erythrocyte deformability as a possible contributing facto to pulmonary hypertension and ascites in broiler chickens. Avian Diseases, v.35, p.374-9, 1991.

\section{http://dx.doi.org/10.2307/1591192}

NATT, M.P.; HERRICK, C.A. A new blood diluent for counting the erytrocytes and leucocites of chickens. Poultry Science, v.31, p.182-8, 1952.
KANTEK GARCIA-NAVARRO, C.E.; PACHALY, J.R. (Eds). Manual de hematologia veterinária. São Paulo: Varela, 1994. 174p.

PIERSON, F.W. Laboratory techniques for avian hematology. In: FELDMAN,B.F.; ZINKL,J.G.; JAIN, N.C. Schalm's Veterinary Hematology. 5 ed. Philadelphia: Lippincott Williams \& Wilkins, 2000, p.1145-1146.

PINHEIRO, M.R. Manejo de frangos. Campinas: Facta, 1994. 174p.

SAUKAS, T.N. Estudo de variáveis clínico laboratoriais em aves vacinadas e infectadas com vírus da doença infecciosa bursal. 1993. 146 p. Tese (Doutorado em Clínica Veterinária) - Curso de Pós graduação em Clínica Veterinária, Universidade Estadual Paulista, Botucatu.

STURKIE, P.D.; GRIMINGER, P. Body fluids: blood. In: STURKIE, P.D. Avian Physiology. New York: Springer-Verlag, 1986. p.102-129.

TESSARI, E.N.; OLIVEIRA, C.A F.; CARDOSO, A L.S.P.; et al. Parâmetros hematológicos de frangos de corte alimentados com ração contendo aflatoxina $B_{1}$ e fumonisina $B_{1}$. Ciência Rural, v.36, n.3, p.924-929, 2006.

USER'S guide: statistical analysis system. Release 6.11. Cary, NC: SAS Institute, 1996. WINTROBE, M.M. Variations in the size and hemoglobin content of eritrocytes in blood of various vertebrates. Folia Haematology., v.51, p.31, 1933. 